\title{
El Trabajo bajo el neoliberalismo: subcontratación en una universidad estatal chilena
}

\author{
Gloria Zavala-Villalón \\ Universidad de Chile, Santiago, Chile. \\ Email: gzavala@uchile.cl \\ Paula Vidal-Molina \\ Universidad de Chile, Santiago, Chile. \\ Email: pvidal@uchile.cl
}

\begin{abstract}
Resumen: Se muestran las características del trabajo subcontratado de personal de aseo en una universidad estatal chilena. Con un diseño de investigación mixto convergente, los hallazgos muestran altos niveles de riesgo psicosocial, en el cuestionario SUSESO/ISTAS21, además de las siguientes categorías discursivas: (1) problemas de ingresos económicos, (2) pérdida de control sobre la relación laboral, (3) demandas y bajo apoyo institucional, (4) ejercicio de derechos laborales (5) responsabilidad individual e incertidumbre en la construcción del proyecto de vida. Se concluye que la subcontratación laboral produce precariedad y segmentación del colectivo de trabajo, afectando negativamente la salud y subjetividad de los trabajadores.
\end{abstract}

Palabras claves: Subcontrato; universidad estatal; trabajadores no calificados; trabajo precarizado; mujeres; riesgos psicosociales, sociología del trabajo.

\section{Work under neoliberalism: subcontracting at a chilean state university}

Abstract: The characteristics of the subcontracted work of hygiene personnel in a Chilean state university are presented. With a convergent mixed research design, the findings show high levels of psychosocial risk in the SUSESO/ ISTAS21 questionnaire, in addition to the following discursive categories: (1) problems of economic income, (2) loss of control over the labor relationship, (3) demands and low institutional support, (4) exercise of labor rights, (5) individual responsibility and uncertainty in the construction of the life project. It is concluded that labor subcontracting produces precariousness and segmentation of the work group, negatively affecting the health and subjectivity of the workers.

Keywords: Subcontract; state university; unskilled workers; precarious work; women; psychosocial risk; work sociology

\section{Trabalho sob o neoliberalismo: subcontratação numa universidade estatal chilena}

Resumo: O artigo mostra as características do trabalho terceirizado de pessoal de limpeza numa universidade estatal chilena. Com um desenho de pesquisa convergente e misto, os resultados mostram altos níveis de risco psicossocial, no questionário SUSESO / ISTAS21, além das seguintes categorias discursivas: (1) problemas de renda econômica, (2) perda de controle sobre a relação de emprego, (3) demandas e baixo apoioinstitucional, (4) exercício de direitos trabalhistas (5) responsabilidade individual e incerteza na construção do projeto de vida. Conclui-se que a terceirização do trabalho produz precariedade e segmentação do trabalho coletivo, afetando negativamente a saúde e a subjetivida de dos trabalhadores.

Palavras-chave: Subcontrato; universidade estatal; trabalhadores não qualificados; trabalho precário; mulheres; riscos psicossociais; sociologia do trabalho. 


\section{Introducción}

América Latina es la región con mayor subcontratación en el mundo, después de Europa y Norteamérica. En Chile, se observa un aumento sostenido en los últimos 10 años de formas de contratación temporal, desprovista de derechos laborales y bajos salarios favoreciendo la precarización y la desigualdad en el mercado laboral. Lo anterior, en función de las medidas promovidas posteriores al golpe cívico-militar en Chile, que dieron el sello neoliberal al modelo imperante hasta la actualidad.

A partir de 1994, se comienza un proceso de implementación del denominado Nuevo Management Público (NMP)en las dependencias del Estado, orientado a consolidar un Estado mínimo para garantizar derechos sociales y máximo para el tránsito libre de capitales, generando nuevas interacciones entre lo público y privado, incorporando formas de gerenciamiento, caracterizadas por flexibilidad, relaciones laborales débiles y subcontratación de tareas.

La subcontratación de tareas, como forma de flexibilización laboral, aunque presenta variedad de acepciones, puede definirse comola situación contractual en la cual "una unidad económica con trabajadores a su mando realiza tareas para otra empresa, sea dentro de las instalaciones de esta última o en sus propias instalaciones” (De la Garza, 2012, p. 25).

Este artículo se adentra en la problemática del subcontrato y su impacto en un sector específico del Estado: la universidad estatal, poco estudiada en Chile. Se propone, a partir de una investigación realizada en dos facultades que llevan a cabo estas prácticas, sintetizar hallazgos acerca de las características del trabajo subcontratado- respecto de salud, precarización y subjetividad de los trabajadores- en este tipo de institución.

A continuación, el lector encontrará una serie de apartados que dan cuenta 1) del contexto que explica las transformaciones en Chile posteriores a 1973, en el plano educacional y del trabajo, y un marco conceptual para comprender estas transformaciones, 2) los detalles metodológicos de la investigación 3) los hallazgos que particularizan la problemática en la universidad estatal, y 4) por último, se avanza en algunas ideas que cristalizan los hallazgos, abiertos a seguir el debate y formular nuevas preguntas.

\section{Transformaciones del capitalismo: neoliberalización en Chile}

Entre 1945 y 1970, tuvo lugar un crecimiento generalizado de las economías de los países centrales. El capitalismo industrial, con su patrón de desarrollo productivo fordista, entró en crisis a principios de 1970, enfrentando un aumento sin precedentes de la competencia en los mercados internacionales, y generando presiones hacia gobiernos y empresas por flexibilizar los mercados de trabajo, para mantener el ritmo de acumulación(Kalleberg, 2012).

La respuesta del Capital se orientó a desvalorizar la fuerza de trabajo bajo una reestructuración productiva de acumulación flexible, caracterizada por privatización de servicios, desregulación de la política económica, predominio progresivo del capital financiero, promoción de la tercerización, y precarización de la seguridade ingresos del empleo (Antunes, 2011; Beck, 2000; Garretón, 2012; Sennett, 2000). El papel del Estado se redujo

considerablemente, descentralizando sus agencias, conllevando la desregulación y descolectivización de las relaciones laborales y el surgimiento de formas de empleo atípicas, en una estructura marcada por las desigualdades en la distribución de la riqueza (Castel, 1997; Kalleberg, 2012). Disminuyendoel proletariado tradicional y aumentando el "nuevo proletariado fabril y de servicios, presente en las diversas modalidades del trabajo precario" (Antunes, 2011, p. 48).

Este patrón de acumulación, orientado al crecimiento económico permanente basado en la explotación del trabajo vivo, contempla la dinámica tecnológica y organizacional intrínseca del capitalismo, definido como sistema neoliberal, que implica no solo un modelo económico, sino cultural, político y social (Harvey, 1992). 
En Chile, el golpe de Estado de 1973 y la dictadura militar que se mantuvo hasta 1989, marcó la implementación de políticas fuertemente neoliberales a todo nivel, reduciendo el empleo público y disminuyendo los beneficios de los trabajadores,con un reconocimiento mínimo de los derechos laborales relacionados con trabajo decente (Cárdenas, Link yStillerman, 2012). Lo anterior no cambió sustancialmente durante los gobiernos de la Concertación, a pesar de las reformas al Código del Trabajo realizadas de vuelta a la democracia, convirtiéndose Chile en un ejemplo de flexibilidadextremo, sin políticas de seguridad social para los trabajadores (Cárdenas, Link yStillerman, 2012; Kalleberg, 2012). Conllevando el enfrentamiento de los sujetos a la falta de garantías sociales y legales, bajas remuneraciones y exposición a altos riesgos de salud, siendo las mujeres quienes más probabilidades tienen de contar con empleos precarios (Kalleberg, 2012).

En este sentido, entenderemos trabajo precario “como aquel trabajo que es frágil, impredecible e inseguro, y en el cual los trabajadores asumen los riesgos del empleo en vez de las empresas o los gobiernos” (Ibid, p. 41).

En relación a lo anterior, cabe destacar los planteamientos de Cuevas (2015) referentes a que la aparición de categorías de trabajadores precarios en Latinoamérica, no se corresponde con los marcos de discusión dominantes referidos a los retrocesos de los estados de bienestar europeos, siendo categorías sociales de larga data, invisibilizadas por estos marcos. En este sentido, en América Latina "el trabajo precario frecuentemente ha sido un elemento constitutivo dela estrategia de desarrollo de las élites dirigentes que conciben a sus países comojugadores subalternos sometidos a la influencia de instituciones financierasinternacionales” (Ibid, p. 11).De esta manera, las categoríaslatinoamericanas no calzan con la figura dominante del trabajador (hombre,sindicalizado, capacitado y ciudadano), apuntando a categorías marginales (trabajadores con baja calificación laboral, mujeres, inmigrantes, etc.).

\section{Universidad estatal y empleo: nuevas configuraciones bajo el neoliberalismo}

En el mundo del trabajo, las transformaciones posteriores al golpe cívico-militar, que dieron el sello neoliberal al modelo de desarrollo imperante en el Chile, impactaron en los lineamientos de la legislación laboral chilena (aún vigente), con base en el llamado Plan Laboral de 1979, que flexibilizó el empleo, restringió la acción sindical y amplió márgenes de externalización productiva (Cárdenas, Link yStillerman, 2012). Este funcionamiento, dejó desprotegidos a los trabajadores subcontratados en sus derechos sociales y laborales. Frente a ello, en 2007 entró en vigencia la ley N²0.123, que regula el empleo bajo ese régimen; con mayor claridad en la definición legal de subcontratación ${ }^{1}$ : la organización principal amplía sus responsabilidades respecto de las condiciones laborales de los trabajadores, siendo "solidariamente” responsable por su cumplimiento. La ley avanza sin cuestionar la idoneidad del régimen.

En las organizaciones públicas, a nivel legal, la ejecución de la ley 18.834 en 1989, en plena dictadura, que vino a regular el sector estatal, estableció que los cargos de planta o contrata ${ }^{2}$ solo corresponden a funciones “propias” de las instituciones y las demás actividades pueden ser realizadas por el sector privado, avalando la externalización. Por otro lado, a partir de 1994, con los gobiernos de la Concertación de Partidos por la Democracia, comienza un proceso de implementación del NMP en las diversas dependencias del Estado, incorporando formas de gerenciamiento ${ }^{3}$ propias de empresas privadas. Las organizaciones públicas empiezan a buscar eficiencia, mediante la descentralización, la gestión por objetivos, el incentivo monetario al cumplimiento de tareas y la subcontratación para externalizar tareas fuera de su giro (Waissbluth e Inostroza, 2007).

En el campo de la educación, dicha transformación se reflejó en la disminución del gasto público, que cayó del 35\% al 15\% entre 1974 y 1980, forzando a las universidades estatales a abandonar la gratuidad, cobrar aranceles y buscar otras fuentes de financiamiento. En concreto, el autofinanciamiento creció en promedio de un 13.5\% al 26.9\% entre 1965 y 1980 (Bernasconi yRojas, 2003, p. 20). En paralelo, con las reformas de 1981, se permitió la expansión de la educación universitaria privada, bajo el principio de "libertad de enseñanza”, facilitando la apertura de establecimientos con el argumento de regular la calidad de la educación, a partir de una mayor competencia en el mercado;llegando a su apogeo en los gobiernos de la Concertación (1990-2010), ya que se mantuvo el espíritu de las reformas llevadas a cabo en dictadura. Lo anterior se ve reflejado en las 
palabras de José Joaquín Brunner ${ }^{4}$, quien planteó que la política pública universitaria debía orientarse a: generar "una sana competencia entre las universidades por atraer a los mejores postulantes, tendiendo así a elevar la calidad de la docencia” y eliminar de manera definitiva la educación gratuita, planteando que esta implicaría "un simple disfraz demagógico para ocultar el hecho de que su costo se traslada a la comunidad, recayendo la carga en sectores de menores ingresos que los beneficiados” (Brunner, 1992, p. 55).

Para el año 2002, el sector privado representaba el 75\% de las instituciones de educación superior del país y el $100 \%$ del sector no-universitario de la educación superior(Bernasconi y Rojas, 2003). Los planteles universitarios en general aumentaron progresivamente, llegando de 8 en 1981 a 59 en 2017 (Downey y Portiño, 2017).A la par, la matrícula universitaria aumentó significativamente de 116.000 estudiantes en 1980 a 645.492 el año 2016 (Consejo Nacional de Educación, 2016).

En definitiva, esta disminución del aporte estatal directo a las universidades del Estado, las obligó a buscar fórmulas para optimizar recursos bajo una lógica de competencia.

La neoliberalización impactó a la universidad, y su evidencia es la creación de universidades privadas, lucro, instalacióndel arancelamiento de la formación universitaria, prácticas de gestión vinculadas al NMP, exigencias productivistas al cuerpo académico y orientación de la formación a las necesidades del mercado o, como lo ha dicho Chomsky (2014), hoy en la universidad operan contratos inestables, profesores temporales, flexibilización laboral, bajos salarios, escasa participación de la comunidad universitaria en la toma de decisiones, aumento de puestos administrativos, y jóvenes sometidos a la presión de créditos y deudas. Se inicia la era del "capitalismo académico", en que la universidad pasa de un enfoque social y científico en cuanto a investigación y formación a la "universidad emprendedora”, basada en la lógica neoliberal de la competencia y el mercado (Slaughter y Leslie, 1998).

Las universidades estatales compiten en desventaja en el mercado, con la necesidad urgente de cambiar sus formas de gestión y estructura burocráticas, por aquellaspropias de las universidades privadas, orientadas hacia una mayor eficiencia. Lo anterior, implicó la introducción de figuras tales como el subcontrato, en distintos ámbitos (Downey y Portiño, 2017).

Debido a su regulación, en las universidades estatales los trabajadores bajo este régimen no son reconocidos como parte de los trabajadores del sector público, no teniendo la posibilidad de ingresar a la Administración del Estado, a menos que se lleve a cabo un concurso público, o a través de la voluntad de los Rectores, de los planteles (Ibid).

Downey y Portillo (Ibid), encuentran puntos en común al analizar cinco estudios ${ }^{5}$ sobre subcontratación en universidades chilenas (cuatro estatales y una privada tradicional), destacándolecomo un fenómeno que se concentra en servicios auxiliares: aseo, seguridad y jardinería. Lo que implica una composición de trabajadores que ocupan una posición de desventaja en el mercado de trabajo, por lo general mujeres, de edad avanzada y bajo nivel educacional, con clara división sexual del trabajo, en que los hombres desempeñan en labores de vigilancia y las mujeres labores de limpieza.

Este suministro de trabajadores subcontratados con baja calificación laboral, realizando actividades de baja o nula especialización, conllevaría, según Echeverría (2006), un desmedro en las condiciones de trabajo tanto en términos de remuneraciones y seguridad social, como de riesgos y desprotección en cuanto a higiene y seguridad laboral.Así, la degradación de las condiciones de trabajo, implica precarización en cuanto a mayor exposición a riesgos para la salud, como los riesgos psicosociales, definidos como "aquellas características de las condiciones de trabajo y, sobre todo, de su organización que afectan a la salud de las personas a través de mecanismos psicológicos y fisiológicos” (Moncada, Llorens yKristensen, 2002, p. 14). Siendo centrales el control sobre el contenido de las tareas, las exigencias, el apoyo social y el nivel de compensaciones por el trabajo realizado (Ibid).

Otro aspecto en común en los estudios analizados, apunta a la inestabilidad laboral, representada en la escasa antigüedadde los trabajadores. También se agregan salarios menores al ingreso medio nacional, que 
llevan a la realización de horas extras para compensar las precarias remuneraciones. Lo anterior, se une a la inexistencia de acción colectiva y sindicalización, por miedo a represalias o a mayor precarización de su situación laboral (Downey y Portillo, 2017).

Esta situación genera en un mismo espacio, tipos diferenciados de trabajadores, según empleador directo, en relación a formas de precariedad e inseguridad invisibilizadas (Echeverría, 2010; López, 2008;Neffa, 2012).

Lo anterior, pone en juego la concepción que se tiene de universidad estatal como universidad pública, orientada al bien público y no al servicio de intereses particulares (Atria, 1 noviembre, 2016).

\section{Subcontratación y sentidos del trabajo}

La segmentación del colectivo de trabajo, que produce la subcontratación laboral, dividiéndolo en un mercado primario y uno secundario o externo; disminuye sus posibilidades de negociación colectiva (Echeverría, 2013).

Adicionalmente, la predominante estructuración de sindicatos solo a nivel de las empresas- y la prohibición de sindicalización y huelga en el servicio público en Chile- han implicado una fragmentación del tejido social de reivindicaciones laborales característico en las décadas de los '60 y '70 en la región (Iranzoy Richter, 2012). Lo anterior se agudiza en el caso de los trabajadores subcontratados, mostrando mínima comunicación con sindicatos en ambas direcciones, en consideración a la legislación y al temor frente a la posibilidad de perder su fuente laboral, más la alta rotación y la diversidad de turnos, implica dificultades para generar lazos de identificación tanto con el lugar de trabajo, como con pares, ya que no se comparten tiempos, espacios, ni tareas (Iranzoy Richter, 2012; Lay, Trebilcock, Olivares y Durán, 2014). Es debido a esta dispersión y fragmentación, características de la subcontratación, que se dificulta la construcción de identidades colectivas en el espacio laboral (Cárdenas, Link yStillerman, 2012).

Finalmente, el género y la calificación laboral aparecen como aspectos que dan cuenta de la segmentación del mercado de trabajo. Es decir, trabajos con baja o nula calificación laboral y menor relevancia organizacional, en contextos tayloristas y precarios, enmarcan la reproducción de la división sexual del trabajo, conllevando mayor presencia de mujeres en este tipo de actividades (Iranzoy Richter, 2012).

En esta línea, Cárdenas et al. (2014), en su estudio trayectorias laborales de la clase media-baja en Chile, refieren que las trayectorias laborales de mujeres muestran condiciones más precarias, particularmente en casos donde carecen de oficio o profesión, tienen educación escolar incompleta y/o provienen de hogares de escasos recursos. Lo que se suma a su doble jornada, en trabajo remunerado y trabajo doméstico y de cuidado no remunerado, que se mantiene como función principal asociada al género (Cárdenas, Link yStillerman, 2012; Cárdenas et al., 2014). En esta línea, las autoras identifican en la Trayectoria definida como Subordinada, a aquellas mujeres jefas de hogar, de baja escolaridad y sin especialización laboral, que llevan a cabo principalmente tareas de aseo y ornato; conformando una subjetividad laboral funcional a la sociedad de servicios neoliberal, donde no hay cabida para la transformación de sus condiciones de trabajo a través de la eficacia personal o colectiva, percepción predestinación laboral y de vida negativas(Cárdenas et al., 2014).

Esto es relevante, ya que el trabajo en la era de la flexibilización mantiene su rol de centralidad y estructuración de la vida material, mediante la urgencia por el logro de metas, alta demanda de implicación subjetiva y disminución de límites entre los ámbitos laboral y personal; cuyo valor está dado por necesidades y proyectos individuales, en una trayectoria singular, inestable y marcada por la transitoriedad (Díaz, Godoy y Stecher, 2005). Involucra la construcción de sentidos e identidades laborales funcionales a las nuevas culturas laborales (Díaz et al., 2005; Godoy et al., 2014; Soto, Espinoza y Gómez, 2008) y, como ya se mencionó, mayores riesgos psicosociales en el trabajo (Pérez-Franco, 2016). El trabajo, incapaz de asociarse a un proyecto de vida, aparece como un hecho contingente, fragmentado, orientado solo a la sobrevivencia(Iranzoy Richter, 2012). 


\section{Aproximación metodológica}

Para conocer las características del trabajo subcontratado en el ámbito universitario estatal, se realizó una investigación en dos facultades que llevan a cabo estas prácticas, con foco en personal de aseo, en una universidad del Estado de Chile dela región Metropolitana.

El diseño fue mixto convergente, con recolección concurrente de datos cuantitativos y cualitativos, y análisis de la información para luego integrarla (Creswelly Plano, 2011).

Levantamiento de datos cuantitativos: buscó obtener información sobre aspectos relacionados con condiciones laborales y riesgos psicosociales en el trabajo. Para esto último, se utilizó el cuestionario SUSESOISTAS21 (versión breve)(Alvarado et al., 2012).Este cuenta con 20 preguntas, agrupadas en cinco dimensiones: (1) Exigencias psicológicas: cuantitativas, cognitivas, emocionales y sensoriales. (2) Trabajo activo y desarrollo de habilidades: autonomía respecto del trabajo, posibilidad de desarrollar habilidades, control sobre tiempos de trabajo, sentido del trabajo e identificación con la institución. (3) Apoyo social en la empresa y calidad del liderazgo: claridad de rol, calidad de liderazgo y de relación con superiores y compañeros. (4) Compensaciones: reconocimiento, trato justo, seguridad sobre condiciones contractuales. (5) Doble presencia: preocupación por el trabajo doméstico a la vez que por las tareas propias del trabajo (Candia, Pérez-Franco y González, 2017). Fue aplicado a 61 trabajadores subcontratados de aseo, de ambos sexos, buscando asegurar la mayor cobertura en función de la cantidad de trabajadores en cada unidad ${ }^{6}$. Adicionalmente, se levantó información sobre características sociodemográficas y de ingresos. El detalle de la muestra es el siguiente:

Tabla 1.

Muestra de trabajadores de aseo según facultad (en absoluto y porcentaje)

\begin{tabular}{|c|c|}
\hline Facultad & Servicio de Aseo \\
\hline Facultad 1 & 51 \\
\hline$\%$ cobertura & $60-72,9 \%$ \\
\hline Facultad 2 & 10 \\
\hline$\%$ cobertura & $83,3 \%$ \\
\hline
\end{tabular}

Fuente: Elaboración propia, en base a Boccardo, Cornejo, Gómez, Vidal y Zavala (2015).

Levantamiento de información cualitativa:buscó comprender en profundidad los discursos de las participantes. Se realizaron cuatroentrevistas semi-estructuradas, a través de muestreo intencionado, buscando cubrir distintas posiciones de sujeto, con criterio dado por facultad y labores de aseo subcontratadas. El foco estuvo en mujeres, considerando su mayor presencia en este tipo de actividades, como ya se mencionó. Las entrevistas correspondieron a tres trabajadoras y a una supervisora de las empresas subcontratistas. La supervisora se incluyó considerando su trayectoria laboral, quientambién se desempeñócomo auxiliar de aseo en la misma empresa, permitiéndole tener una visión desde dicha posición, y de la posición de organización del trabajo desde la administración operativa.

Las entrevistas fueron grabadas digitalmente, previa autorización a través de consentimiento informado. Una vez transcritas, fueron tratadas con análisis de contenido cualitativo, conel software ATLAS.ti 7. Finalmente, se interpretaron integradamente los datos cuantitativos y cualitativos.

\section{Análisis de hallazgos}

El número de trabajadores de aseo de ambas facultades, bordea las 82 personas, y del total encuestados (61), casi el 80\% corresponde a mujeres. El 25\% de la muestra se ubica entre los grupos etarios de 25-30 años y un $10 \%$ corresponde a más de 60 años. Cerca del $80 \%$ posee menos de 12 años de escolaridad, es decir, no 
cuentan con el nivel de calificación que les permita optar a trabajos con mejores condiciones salariales o contractuales. Aquí, la relación entre género (mujeres), edad (jóvenes o en edad de jubilación) y nivel de escolaridad (bajo) predeterminan el lugar y condiciones de empleo precarias ofrecidas a estas trabajadoras.

A ello se suma que más del 60\% de estas trabajadoras cumplen la función de principal sostenedora del hogar y más del $80 \%$ no cuenta con un segundo empleo que complemente el salario recibido.

Los resultados cuantitativos mostraron un alto riesgo psicosocial para el personal de aseo de ambas facultades, en cuatro de las cinco dimensiones del cuestionario SUSESO/ISTAS21, a saber: trabajo activo y desarrollo, excede considerablemente en ambas facultades el tercio de trabajadores que presentan alto riesgo para la salud, en la Facultad 1 el aseo presenta un 66,7\%, y en la Facultad 2 un 80\%. En la dimensión apoyo social en la empresa y calidad del liderazgo, se observó 52\% en de riesgo en la Facultad 1 y $77.8 \%$ en la Facultad 2. En la misma línea, compensaciones, presentó 60,8\% en la Facultad 1 y 66,7\% en la Facultad 2. Finalmente, la dimensión doble presencia, mostró 78.4\% para la Facultad 1, y 60\% en la Facultad 2.

La única dimensión con bajo nivel de riesgo fue exigencias psicológicas, con 33,3\% de trabajadores de aseo de la Facultad 1, y un $40 \%$ en la Facultad 2 en riesgo psicosocial. Una explicación plausible respecto de este resultado, dice relación con que son las exigencias cuantitativas (carga de trabajo), las que predominan en los discursos de las trabajadoras, con mínima mención respecto de los otros tipos de exigencias.

Por su parte, en el análisis cualitativo surgieron cinco categorías: (1) problemas de ingresos económicos, (2) pérdida de control sobre la relación laboral, (3) demandas y bajo apoyo institucional, (4) ejercicio de derechos laborales: naturalización de la precariedad y, (5) responsabilidad individual e incertidumbre en la construcción del proyecto de vida.

A continuación se integran estos hallazgos, desarrollando las categorías cualitativas, dentro de las cuales se realizan las conexiones con las dimensiones del cuestionario aplicado.

\section{(1) Problemas de ingresos económicos}

Los datos arrojan que las remuneraciones son cercanas al umbral de la línea de la pobreza ${ }^{7}$. Mostrando una situación salarial empeorada (casi en un 50\%) de la tendencia entregada por el Estado, que bordea los 440.000 pesos (Durán et al., 2016) ${ }^{8}$. Véase Tabla $2^{9}$ :

Tabla2.

Detalle de remuneraciones

\begin{tabular}{|c|c|c|c|c|c|c|}
\hline $\begin{array}{l}\text { Servicio } \\
\text { Aseo }\end{array}$ & $\begin{array}{c}\text { Ingreso } \\
\text { líquido } 10\end{array}$ & $\begin{array}{c}\text { Total } \\
\text { Ingresos } \\
\text { (con horas } \\
\text { extras o } \\
\text { segundo } \\
\text { empleo) }\end{array}$ & $\begin{array}{l}\text { Ingreso total } \\
\text { Per-cápita }^{11}\end{array}$ & Deuda $^{12}$ & $\begin{array}{l}\text { Ingreso total } \\
\text { con deuda } \\
\text { incluida }\end{array}$ & $\begin{array}{l}\text { Ingreso total } \\
\text { Per-cápita }\end{array}$ \\
\hline Facultad 1 & $\begin{array}{c}393,9 \text { US\$ } \\
(\$ 263.000)\end{array}$ & $\begin{array}{c}\$ 467,78 \text { US\$ } \\
(\$ 312.333)\end{array}$ & $\begin{array}{c}\$ 189,46 \text { US\$ } \\
(\$ 126.500)\end{array}$ & $\begin{array}{c}\text { \$184,71US\$ } \\
(\$ 123.333)\end{array}$ & $\begin{array}{c}\text { \$283,06US\$ } \\
(\$ 189.000)\end{array}$ & $\begin{array}{c}\$ 110,83 \mathrm{US} \$ \\
(\$ 74.000)\end{array}$ \\
\hline Facultad 2 & $\begin{array}{c}\text { \$389,37US\$ } \\
(\$ 259.977)\end{array}$ & $\begin{array}{c}\text { \$444,52US\$ } \\
(\$ 296.800)\end{array}$ & $\begin{array}{c}\begin{array}{c}\$ 205,76 \text { US } \$ \\
(\$ 137.388)\end{array}\end{array}$ & $\begin{array}{c}\text { \$255,89US\$ } \\
(\$ 170.856)\end{array}$ & $\begin{array}{c}\$ 188,62 \text { US\$ } \\
(\$ 125.944)\end{array}$ & $\begin{array}{c}\$ 112,8 \text { US\$ } \\
(\$ 75.320)\end{array}$ \\
\hline
\end{tabular}

Fuente: Elaboración propia, en base a Boccardo et al. (2015)

Los discursos de las trabajadoras de aseo corroboran lo anterior, cuando señalan que:

“No alcanza la plata. Es muy poca plata. Cumplían con las fechas de pago porque tampoco teníamos beneficios de nada, no nos regalaban ni siquiera un bono para las... para la pascua, para el dieciocho, un incentivo, nada, era tu sueldo...”(Trabajadora de aseo 2). 
Se suma la alta flexibilidad contractual que sufren, expresada en jornada laboral e inestable cumplimiento de obligaciones relacionadas con el pago de los derechos sociales en el salario. En este sentido, se indica que no hay seguridad respecto de la continuidad en el empleo, además de plantear que los descuentos por concepto de salud y seguro privado de pensiones disminuyen el monto de sus remuneraciones,

"estos dos meses que estamos en horario, lo van a pagar a trescientos sesenta y dos, y después si es que nos llegaran a contratar en marzo, ahí lo van a disminuir, porque ahora estos dos meses estamos con boletas, y este otro mes de marzo empezamos con descuentos, por la salud y toda esa cuestión...” (Trabajadora de aseo 3).

Dicha situación genera alta rotación de trabajadoras, en busca de mejores condiciones laborales,

“los sueldos y no, y no, hayan muy poco y yo igual encuentro que están muy bajos los salarios (...) la gente se prefiere ir a la construcción (...) les va mejor en la construcción y ahora con todas las leyes de las nanas ${ }^{10}$, toda la gente se está yendo a trabajar de nana, yo tenía una excelente señora (...) y me dijo "lo siento, pero yo me voy de nana porque...”, claro po, están ganando más, tienen más beneficios” (Supervisora empresa de aseo).

Adicionalmente, se plantea como parte de la flexibilidad contractual, la inestabilidad en los contratos con duración anual, sin seguridad de continuidad,

“nos contrataban durante el año y nos finiquitaban y nos volvían a contratar como subcontrato (...) Nos pagaban nuestro sueldo el 30 de enero y después nos daban una fecha para cobrar el finiquito, que era por ahí por enero, febrero, los primeros días de febrero (...) y después nos contrataban en febrero, nos hacían el subcontrato” (Trabajadora de aseo 1).

Lo anterior, concuerda con los altos niveles de riesgo en la dimensión Compensaciones del SUSESO/ ISTAS21, implicando una percepción de bajo reconocimiento por el trabajo realizado.

\section{(2) Pérdida de control sobre la relación laboral}

Se observa escasa posibilidad de tomar decisiones respecto a tiempos y ritmos de trabajo, así como alta subordinación en la relación con sus supervisores directos.

"Sí, uno de repente se estresa. Una se enferma porque es tanto el trabajo que uno tiene que sacarlo. Tu no podi dejar el trabajo ahí. Porque si tú lo dejai ahí o lo dejai mal hecho llegan los reclamos (...) llaman al mayordomo, uno tiene que volver a ver qué paso” (Trabajadora de aseo 1).

Concordando con lo anterior, el SUSESO/ISTAS21 da cuenta de percepción de bajo nivel de autonomía y bajo control sobre los tiempos de trabajo, ya que la dimensión Trabajo activo y desarrollo, excede considerablemente en ambas facultades el tercio de trabajadores que presentan alto riesgo para la salud.

La jornada laboral para estas trabajadoras dura 48 horas, es decir, más de las 45 legales permitidas. La flexibilidad en la jornada, en algunos casos, está en función de las necesidades de la empresa, haciendo evidente bajos niveles de autonomía,

“ahí trabajamos duro, o sea no es cuestión de que uno se iba a sentar un minuto y a descansar, yo no descansaba nada. (...) trabajaba de lunes a sábado, de siete a tres y media de la tarde (...) ahí empezaba mi ritmo de trabajo, a las 10 a colación, después volver a las 11 empezar otra vez a trabajar (...) hasta las tres y media, (...) y después entraban a las dos de la tarde el turno de tarde (...) hasta las diez de la noche. (...) si siempre me dicen [sus hijos], 'no trabaji tanto que esto, te estai matando trabajando’” (Trabajadora de aseo 3).

El alto riesgo psicosocial en la dimensión Compensaciones del SUSESO/ISTAS21, también daría cuenta de esta inseguridad respecto de las condiciones de trabajo. 


\section{(3) Demandas y bajo apoyo institucional}

Los resultados cualitativos, evidencian una alta carga de trabajo, tiñendo el tono emocional de las trabajadoras, en ámbitos más allá del trabajo remunerado, afectando su ánimo y sus relaciones familiares,

"cuando me decían que llegaba muy cansada y a veces llegaba enojada a mi casa, entonces me decían ‘vienes con la maña’, entonces no te quedes más, si vienes muy cansada...” (Trabajadora de aseo 2).

Lo que da cuenta de dificultad para separar los ámbitos público y privado, laboral y familiar, asociada con Doble presencia del SUSESO/ISTAS21.

Por otro lado, los discursos muestran percepciones de escasas posibilidades de apoyo institucional, ligadas a la "responsabilidad solidaria" de la Universidad frente al incumplimiento de obligaciones laborales por la empresa contratista. Observándose concordancia con la baja identificación institucional representada en la dimensión Trabajo activo y desarrollo. Lo anterior, se une a condiciones de trabajo no siempre adecuadas, unida a la desvalorización de ellas como trabajadoras, ejemplificada con la descripción de ellas como grupo, con apelativo de "animalitos",

"teníamos unos casilleros ahí, todos amontonados, que una vez vino de la Inspección del Trabajo e hicieron desaparecer todas esas cuestiones, porque parecíamos animalitos ahí todas juntas” (Trabajadora de aseo 3).

El conflicto de pertenencia organizacional, también se refleja en diferencias jerárquicas implícitas entre trabajadores internos y subcontratados, distinguiéndose trabajadores de primera y segunda categoría. Así, la calidad de relación con superiores y compañeros de trabajo aparece mermada, encontrándose porcentajes de alto riesgo psicosocial en la dimensión Apoyo social en la empresa y calidad del liderazgo del SUSESO/ISTAS21. Lo anterior, también será relevante en relación a la doble subordinación.

La percepción de bajo reconocimiento del trabajo que se realiza, de la dimensión Compensaciones, no se ve solamente en términos de salario, sino que también en los discursos de las trabajadoras, señalando que los funcionarios de la Universidad no valoran su trabajo, incurriendo en malos tratos e indiferencia,

"los únicos que lo valoran [su trabajo] eran los estudiantes. Porque tampoco las jefas nos valoraban, nunca nos dijeron "oye chiquilla...eh...haces bien tu trabajo" nunca nos dijo nada (...) [A los funcionarios] les daba lo mismo. En verdad les da lo mismo. Si podían pasar botando basura, lo hacían nomás...” (Trabajadora de aseo 2).

Adicionalmente, esta modalidad contractual implica doble subordinación, donde las trabajadoras son fiscalizadas en sus tareas por la empresa contratista a la vez que por las facultades; generando dificultades diversas- pertenencia organizacional y angustia en su cotidianidad-, dadas por escasa claridad de rol y flexibilidad laboral. Esta doble subordinación no está exenta de ambivalencias en cuanto a la relación con la Universidad, reforzándose la baja identificación institucional relevada en el cuestionario.

“[La] Supervisora, jefa, gritoneaban a la gente, la humillan, las hacían llorar, me dieron muchos problemas aquí con la jefa (...) a una compañera le hicieron desaparecer un bolso que ella tenía y la jefa, o sea, mi compañera le pregunto por el bolso y ella dijo que no lo tenía (...) Y ella la tironeó porque ella le dijo que iba a acusarla [con administrador de la facultad] y ella le dijo "anda acusarme” y le chispeó los dedos, y después la tiró para afuera y ella salió llorando y la fue a acusar [con administrador de la facultad], y le dijo que se quedara tranquila...” (Trabajadora de aseo 2).

\section{(4) Ejercicio de derechos laborales: naturalización de la precariedad}

En relación a sus derechos sociolaborales, los discursos indican que existe casi un nulo ejercicio de estos. El sentido del trabajo se ve afectado, concordando con la dimensión Trabajo activo y desarrollo, refleján- 
dose en la naturalización de su percepción como trabajadoras, en términos de vulnerabilidad, precarización y exclusión. En la cita la empresa contratista impide el cumplimiento derechos laborales básicos, en función de una lógica mercantil, desvalorizando e invisibilizando a las trabajadoras, quienes perciben la injusticia, pero cuyo relato da cuenta de prácticas comunes frente a las cuales prima la indefensión y la imposibilidad de tomar acción para cambiar la situación,

"hubo una de mis compañeras... parece que se torció la pierna (...) y...ella fue a hablar con las supervisoras pa que la mandaran a la mutual ${ }^{11}$ y la jefa no quiso mandarla porque habían (...) muchas demandas de que había mucha gente que se iba a la mutual. Entonces eso a ellos les perjudicaba como empresa, le sacaban multa (...) Entonces a esa compañera no le prestó ayuda” (Trabajadora de aseo 2).

En contrapeso, es el estamento estudiantil quien ha cumplido un rol de concientización de las demandas por mejoras en dichas condiciones,jugando un rol esencial en cuanto a entregar a las trabajadoras un soporte institucional, que aunque informal, ha dado pie para problematizar su situación laboral, empoderándolas y abogando por sus derechos,

“es que lo que pasa es que por eso nosotras andábamos a escondidas viéndonos con los chiquillos y informando lo que estaba pasando, porque ellas nos tenían prohibido hablar con los chiquillos” (Trabajadora de aseo 2).

Lo anterior muestra la existencia de prohibiciones de relación entre trabajadoras y estudiantes. Existen prácticas anti-sindicales ejercidas por las empresas, que potencian la desprotección social y precariedad laboral, lo que queda en evidencia en el relato de una de las trabajadoras,

"Una compañera años atrás quiso hacer un sindicato. Y qué pasó, la echaron (...) Ella lo que quería hacer es... es reunir gente que firmara pa formar un grupo. (...) La jefa se enteró y...echaron a mi compañera que ella llevaba como cuatro o cinco años (...) y echaron al resto también que estaban firmando pa eso" (Trabajadora de aseo 2).

Esta inseguridad respecto de condiciones laborales, también se ve reflejada en la dimensión Compensaciones, anteriormente desarrollada.

\section{(5) Responsabilidad individual, sacrificio e incertidumbre en la construcción del proyecto de vida}

La alta incertidumbre a nivel subjetivo y las extenuantes jornadas de trabajo, hacen patente las dificultades de las trabajadoras para cubrir tanto sus necesidades básicas, como para conciliar vida laboral y familiar, considerando su doble jornada de trabajo remunerado y reproductivo no remunerado, aumentando la percepción de precarización.

El que la mayoría de las trabajadoras cumpla el rol de principal sostenedor del hogar, tensiona más esta situación. Observándose alta incidencia de riesgo psicosocial relacionado con el trabajo la dimensión Doble presencia del cuestionario aplicado.

En palabras de una de las trabajadoras,

"Entraba a las siete, sí, y ahí trabajaba hasta las tres, después descansaba una o dos horas y después volvía a retomar el turno de las cinco hasta las diez (...) No tenía vida familiar ni personal... porque mis hijos, yo me venía y estaban durmiendo (...) llegaba como las once a mi casa (...) porque si no, no me alcanzaba con lo que yo ganaba en media jornada no me alcanzaba para vivir [ya que] yo soy la que llevo la plata...” (Trabajadora de aseo 1).

El cumplir el rol de sostenedor principal, implica una merma en la calidad de vida a nivel individual y familiar.Observándose en los discursos una lógica sacrificial, en la que se desplaza la gratificación para el futuro, con la finalidad de cumplir con el rol de sostén del hogar. Así, la alta carga de trabajo y la precarización 
del empleo, aparecen como parte de decisiones propias en la construcción del proyecto de vida familiar, sin otra alternativa que asumirlo como un sacrificio individual, pues la dimensión colectiva no es un recurso visualizado como alternativa para aminorar la responsabilidad individual, afectando su sentido del trabajo,

"Pero es que a mí me gusta hacer a veces trabajo po, trabajar, si uno genera plata igual para la casa. (...) lo mío fue muy duro, muy bruto, todo era mucha, mucha pega pero yo igual la hice, no tuve ningún problema. (...) Entonces todas esas cuestiones, ya tengo mis hijos profesionales, gracias a dios (...) Pero todo un sacrificio, si... y espero seguir con el sacrificio para mi nieta que viene que ya tiene dieciséis años...” (Trabajadora de aseo 3).

Esta mirada hacia el futuro se sabe incierta, reconociéndose la inestabilidad en torno a la posibilidad de consecución del proyecto de vida propio,

"Que me contraten, por último hasta los... dos años más o lo que aguante no más... Si yo no espero tener 80 años, quedarme aquí, o sea, es cuestión de... de un poco no más, un poco tiempo, unos tres años... según, porque uno, usted sabe que uno nunca sabe el camino... que le puede llegar alguna enfermedad, y hasta ahí llega...” (Trabajadora de aseo 3).

Esta inestabilidad también está dada por privaciones a nivel de calificación laboral y educativa, lo cual las despoja de libertad a la hora de encontrar alternativas laborales, que cumplan condiciones de seguridad social y reconocimiento. Las privaciones aparecen como determinantes de trayectorias no deseadas, vividas como inevitables, algo que se debe "aguantar". La imposibilidad de desarrollar empleabilidad y la mínima valoración de su labor, se asocian a una visión negativa del futuro, de sí mismas como trabajadoras y de sus habilidades, sin posibilidades de cambiar su situación.

“Sí, siempre se acercaban a mí y me decían "tú puedes postular para otra cosa”, pero cuando llegaba el momento pedían cuarto medio y ahí ya no...” (Trabajadora de aseo 2); “(...) yo sabía que en ninguna otra parte me iban a aceptar po. Únicamente en la empresa de aseo y qué más...tenía que aguantar no más po” (Trabajadora de aseo 3).

La incertidumbre respecto del futuro y la imposibilidad de desarrollarse en el ámbito laboral, ligadas a su baja calificación laboral, también se plasman en las dimensiones Compensaciones y Trabajo activo y desarrollo de habilidades del SUSESO/ISTAS21, ya mencionadas.

\section{Discusión}

Los resultados dan cuenta que, siguiendo a Neffa (2012) y a Echeverría (2013), esta modalidad de contrato, principalmente en casos de trabajadores con baja calificación laboral, contribuye a la naturalización de la precarización, ampliando los ámbitos de exclusión social. La precarización permea los límites de la salud física y mental de los trabajadores, con altos niveles de riesgo psicosocial, en concordancia con los discursos de las participantes. Lo anterior, en el caso de la subcontratación, es interseccional al nivel educacional, el acceso a la educación y al género, con marcada presencia femenina.

No es solo el ámbito del trabajo el que se ve afectado, sino que el complejo flujo de fenómenos que conlleva este tipo de contratación, permeando la trayectoria vital y familiar de cada una de las trabajadoras, en una indefensión cotidiana, con bajas condiciones de posibilidad para ejercer sus derechos laborales (Echeverría, 2013).

Destaca el foco en la familia, en consideración al cumplimiento principal del rol de sostenedoras de hogar. Aparece una lógica sacrificial, desplazando la gratificación hacia el futuro, en consideración a su incertidumbre y en función del aseguramiento, aunque transitorio, del bienestar familiar.

Entre las implicancias laborales, destacan dificultades en términos de pertenencia organizacional e incertidumbre, frente a una organización que contractualmente no tiene la responsabilidad sobre sus condiciones 
laborales. La universidad es sentida lejana, sin que sea posible la construcción de un sentido de pertenencia institucional. Adicionalmente, la desigualdad entre distintos tipos de trabajadores, divididos en funciones y regímenes contractuales, se hace patente. Los contrastes entre ser un trabajador interno de la universidad a ser uno subcontratado, no solo aparecen en las desigualdades de derechos y beneficios laborales, sino que también en el trato cotidiano, diferenciándose trabajadores de primera y segunda categoría, conllevando discriminación.

Aparece flexibilidad en las formas de empleo y polifuncionalidad en las actividades del trabajo, observándose una alta subordinación, con mínimas posibilidades de tomar decisiones sobre su trabajo, pero implicando una respuesta "adaptativa” a las necesidades de la organización, en forma de realización de tareas que no corresponden a las estipuladas contractualmente.

La precarización, expresada entre otros aspectos, en remuneraciones cercanas al umbral de la pobreza y en extenuantes jornadas de trabajo, implican una baja calidad de vida y límites difusos entre los ámbitos personal y laboral, con gran dificultad para conciliarlos. La precariedad aparece naturalizada, no solo en el no ejercicio de los derechos laborales propios; sino en la construcción y realización de la trayectoria y proyecto de vida como responsabilidad única de cada trabajadora. Una trayectoria marcada por la predestinación de lo negativo, una Trayectoria subordinada, femenina, funcional a la sociedad de servicios neoliberal (Cárdenas et al., 2014), en pro de la mantención de una estructura marcada por la desigualdad en la distribución de la riqueza.

Condiciéndose con los objetivos del Plan Laboral, la Ley 18.834 y los propósitos de eficiencia del NMP, se considera a los trabajadores subcontratados como ejecutores de labores higiénicas, no estratégicas para el funcionamiento organizacional, ajenos a la organización en la que laboral.

El neoliberalismo en Chile marca un ejemplo extremo de flexibilización laboral y pérdida de derechos sociales, dando claridad respecto del rol del Estado como subsidiario, facilitador del funcionamiento del mercado y del libre tránsito de capitales, con foco principal en la eficiencia del aparato público. Este foco invisibiliza la precarización, en pos del aprovechamiento de recursos y logro de resultados e nivel estatal, apareciendo como la consigna en el funcionamiento de sus universidades. Lo anterior, reforzado por una lógica de mercado que fomenta la competencia como mejora de la calidad de la educación (Brunner, 1994).

Esta relación con las nuevas formas de gestión del capitalismo y los consecuentes cambios en la forma de gestión del Estado y las dependencias de la universidad estatal, conllevan formas de precarización dadas por la relación de los sujetos con y dentro de la organización.

Las empresas contratistas, emplean trabajadoras con baja calificación para el desarrollo de labores de limpieza, promoviendo y perpetuando su vulnerabilidad y exclusión, dada las condiciones laborales ofrecidas, a la vez que refuerzan la división social del trabajo y el rol de la mujer en labores reproductivas.

Las universidades estatales, sometidas a la competencia descarnada en un mercado que no perdona, buscaron la implantación de regímenes de contratación atípicos, como el subcontrato, bajo la lógica de la eficiencia, para lograr mantener sus recursos frente a la competencia de las universidades privadas, nuevos planteles que funcionaron desde sus inicios desde la lógica del management privado.

Lo anterior, conlleva cambios en las formas en que los trabajadores construyen su sentido en tanto tales. Así como también, construcciones desde distintos ámbitos y actores, respecto de aspectos éticos como de eficiencia; imbricados en un interjuego que requiere una mirada constante respecto de qué significa "agregación de valor” por parte de una organización estatal como es la universidad, y lo que implica responder al trabajo decente. En este sentido, el paso de la universidad estatal al capitalismo académico, a la forma de la universidad emprendedora, conlleva la disyuntiva en que su misión de orientación al bien público, se ve confrontada con su dependenciaa un Estado neoliberal que fomenta y mantiene el debilitamiento de las garantías sociales mínimas para los trabajadores a todo nivel y en todo ámbito. En donde es el mismo Estado quien juega el rol de juez y parte, precarizando a la vez que regulando (mínimamente) el cumplimiento de los (también mínimos) derechos laborales de los trabajadores. 
A modo de corolario, el desafío de hacer visible el fenómeno del trabajo subcontratado fue tomado por el estamento estudiantil en el caso aquí presentado, conllevando un movimiento que permitió la internalización de la mayoría de las trabajadoras de aseo en la universidad. Lo anterior, da cuenta de la construcción de una universidad estatal que aún vive en tensión con las prácticas de gestión del NMP, que se cuestiona la necesidad de una mirada integral de los significados que se construyen en torno al régimen de subcontratación, su idoneidad, no solo en términos de eficiencia, y la necesidad de plasmar en políticas la integración de estas contradicciones, para no instrumentalizar las vidas de quienes se emplean bajo esta modalidad.

\title{
Agradecimientos
}

Este artículo se enmarca en la investigación de Boccardo, G., Cornejo, R., Gómez, C., Vidal, P. \& Zavala, G. (2015). Trabajo subcontratado en FCFM y FACSO. Santiago, Chile: Universidad de Chile.

\section{Notas}

\begin{abstract}
${ }^{1}$ Una organización principal contrata a una empresa para prestar servicios o producir bienes, llevadas a cabo por trabajadores de la empresa contratista, siendo la empleadora de estos (Leiva, 2009).

2 "Planta de personal: conjunto de cargos permanentes asignados por la ley a cada institución. Empleo a contrata: aquel de carácter transitorio que se consulta en la dotación de una institución” (Chile. Decreto con Fuerza de Ley 29, 2004, s.p.).

${ }^{3}$ Recordemos la influencia del libro de 1992 de Osborne y Gaebler en EEUU y en la Administración Pública, "Reinventing Government: How the Entrepreneurial Spirit Is Transforming the Public Sector”. Reading, Md.: Addison-Wesley Publishing Company.

${ }^{4}$ En la época, Presidente del Comité Presidencial de Política de Educación Superior, creado en 1990.

${ }^{5}$ Boccardo, G., Cornejo, G., Gómez, C., Vidal, P. Y Zavala, G. (2015). Trabajo subcontratado en FCFM y FACSO. Informe Final. Universidad de Chile.Santiago, Chile.

Boccardo, G., Moya, C., Ratto, N. y Ruiz, F. (2016). Trabajo subcontratado en el área de aseo en la Pontificia Universidad Católica de Chile. Informe de resultados. Fundación Nodo XXI. Santiago, Chile.

Flores, T. y Ruiz, Y. (2008). Análisis de la externalización de servicios como principal fuente de precarización del trabajo en la Universidad Austral de Chile. Su dificultosa relación con los derechos a la negociación colectiva. Tesina presentada como requisito para optar al Grado de Licenciando en Administración, Universidad Austral de Chile. Valdivia, Chile.

Fundación Sol (2014). La subcontratación en USACH. Santiago, Chile.

Molinet, M. y Montalván, M. (2014). Subcontratación en la UTEM. Trabajo de Titulación para optar al título de Ingeniero Comercial, Universidad Tecnológica Metropolitana. Santiago, Chile.
\end{abstract}

${ }^{6}$ Ver porcentaje de cobertura en Tabla 1.

${ }^{7}$ La línea de la pobreza se encuentra bajo los CLP\$66.084 per cápita, y según la nueva metodología de medición de la pobreza (orientadas por la CEPAL), la nueva línea indica que la pobreza se encuentra bajo los CLP\$136.911 per cápita. (encuesta Casen, 2013). Disponible en http://www.t13.cl/noticia/nacional/estas-son-las-nuevas-lineas-de-la-pobreza-y-la-extrema-pobreza-establecidas-en-laencuesta-casen .

\footnotetext{
${ }^{8}$ Según la encuesta Casen del año 2013, la línea de la pobreza se encuentra bajo los \$105,2 (CLP\$66.084) per cápita, y según la nueva metodología de medición de la pobreza la nueva línea indica que se encuentra bajo los \$218 (CLP\$136.911) per cápita.

${ }^{9}$ El valor en pesos se ha transformado a dólar americano promedio del mes de marzo de 2019 (1US\$=667,68 pesos chilenos), según el Servicio de Impuestos Internos de Chile en relación al dólar observado durante ese año.

${ }^{10}$ Ingreso o salario que recibe el trabajador ya descontado el \% correspondiente a previsión social y salud.

${ }^{11}$ Ingreso por habitante del hogar del trabajador-trabajadora de aseo.

${ }^{12}$ Deuda correspondiente al trabajador/a.

${ }^{13}$ Ingreso per-cápita que queda para cada habitante del hogar del trabajador después de descontada la deuda que posee al ingreso líquido de este.

${ }^{14}$ Se refiere a trabajadoras de casa particular, también llamadas asesoras del hogar.

${ }^{15}$ El témino "mutual”, hace referencia a las Mutuales de seguridad de accidentes del trabajo, trayecto y enfermedades profesionales,
} 
que en Chile son instituciones privadas sin fines de lucro que se encargan de la prevención de riesgo y tratamiento de accidentes y enfermedades laborales.

\section{Bibliografia}

Alvarado, R., Pérez-Franco, J., Saavedra, N., Fuentealba, C., Alarcón, A., Marchetti, N. yAranda, W. (2012). Validación de un cuestionario para evaluar riesgos psicosociales en el ambiente laboral en Chile. RevMed Chile, (140), 1154-1163. doi:10.4067/s0034-98872012000900008

Antunes, R. (2011). O Continente do Labor. Sao Paulo, Brasil: Boitempo.

Atria, F. (1 noviembre, 2016). Autonomía Universitaria y Universidad Pública. El Mostrador.

Bauman, Z. (2000). Trabajo, consumismo y nuevos pobres. Buenos Aires, Argentina: Gedisa.

Beck, U. (2000). Un nuevo mundo feliz: la precariedad del trabajo en la era de la globalización. Barcelona, España: Paidós.

Bernasconi, A. y Rojas, F. (2003). Informe sobre la Educación Superior en Chile: 1980-2003. UNESCO. Recuperado de http://unesdoc.unesco.org/images/0014/001403/140395s.pdf

Boccardo, G., Cornejo, R., Gómez, C., Vidal, P. y Zavala, G. (2015). Trabajo subcontratado en FCFM y FACSO. Santiago, Chile: Universidad de Chile. Recuperado de https://www.researchgate.net/publication/ 305724776TrabajosubcontratadoenFCFMyFACSO

Biblioteca del Congreso Nacional de Chile. (2011). Guía legal sobre: comités paritarios. Chile. Recuperado de: http://www.bcn.cl/leyfacil/recurso/comites-paritarios

Brunner, J. J. (1994).Educación Superior: Chile en contexto internacional comparado. Documento de Trabajo Serie Educación y Cultura N$^{\circ}$ 44. Santiago, Chile: FLACSO-Programa Chile.

Candia, M., Pérez-Franco, J.M. y González, D. (2017). Manual del método del Cuestionario SUSESO/ISTAS21. Versiones completa y breve. Superintendencia de Seguridad Social, Intendencia de Seguridad y Salud en el Trabajo, Unidad de Medicina del Trabajo. Recuperado dehttp://www.suseso.cl/606/articles19640archivo03.pdf

Cárdenas, A., Link, F. y Stillerman, J. (2012) Introducción: ¿Qué significa el trabajo hoy?. En A. Cárdenas, F. Link y J. Stillerman (Eds.) ¿Qué significa el trabajo hoy? Cambios y continuidades en una sociedad global (pp. 17-37). Santiago, Chile: Catalonia.

Castel, R. (1997). La metamorfosis de la cuestión social. Una crónica del salariado. Buenos Aires, Argentina: Paidós.

Cárdenas, A., Undurraga, R., Altschwager, C., Leiva, M., Badilla, M. y Prado, X. (2014). Informe Final: Estudio trayectorias laborales de la clase media-baja en Chile. Programa de las Naciones Unidas para el Desarrollo [PNUD] y Almabrands. Santiago, Chile. Recuperado de http://www.cl.undp.org/content/chile/es/home/library/ poverty/documentos_de_trabajo/informe-final—estudio-trayectorias-laborales-de-la-clase-media-.html

Chile. Decreto con Fuerza de Ley 29 Fija texto refundido, coordinado y sistematizado de la Ley No 18.834 , sobre Estatuto Administrativo, Ministerio de Hacienda (2004, 16 de junio). En Biblioteca del Congreso Nacional de Chile. [en línea]. Recuperado dehttps://www.leychile.cl/Navegar?idNorma=236392\#16-jun-20040 
Chomsky, N. (2014, 13 de marzo). El neoliberalismo tomó por asalto a las universidades. El Espectador.Recuperado de https://www.elespectador.com/noticias/educacion/el-neoliberalismo-tomo-asalto-universidades-noamchomsk-articulo-480438

Consejo Nacional de Educación (2016). Índices 2016. Santiago, Chile: Consejo Nacional de Educación.

Creswell, J. y Plano, V. (2011). Designing and conducting mixed methods research. California, USA: SAGE. Versión Kindle.

Cuevas, H. (2015). Precariedad, precariado y precarización. Polis, 40, 1-15. Recuperado de: http:// journals.openedition.org/ polis/10754

De la Garza, E. (2012). La subcontratación y la acumulación de capital en el nivel global. En J. C. Celis (coord.). La subcontratación laboral en América Latina: miradas multidimensionales. (pp.17-40). Medellín, Colombia: Escuela Nacional Sindical. Recuperado de http://www.izt.uam.mx/sotraem/NovedadesEditoriales/ Subcontratacion.pdf

Díaz, X., Godoy, L. yStecher, A. (2005).Significados del trabajo, identidad y ciudadanía: la experiencia de hombres y mujeres en un mercado laboral flexible. Santiago, Chile: Centro de Estudios de la Mujer.

Downey, M. y Portiño, J.I. (2017). Análisis del subcontrato en las universidades chilenas, especialmente en el caso de las universidades estatales, y las vías jurídicas para su término. Revista Chilena de Derecho del Trabajo y de la Seguridad Social, 8 (16), 81-100. Recuperado de https://revistatrabajo.uchile.cl/index.php/RDTSS/ article/view/48032

Durán, G., Gálvez, R. y Narbona, K. (2016). Salarios en el Sector Público. El mito en torno a los funcionarios del Estado en Chile. Documentos de trabajo Fundación Sol. Recuperado de http://www.fundacionsol.cl/wpcontent/uploads/2016/11/IBV-9-VF151116.pdf

Echeverría, M. (2006). Los riesgos laborales de la subcontratación. Aporte al debate laboral № 19. Departamento de Estudios, Santiago, Chile:Dirección del Trabajo. Recuperado de

Echeverría, M. (2010). La historia inconclusa de la subcontratación y el relato de los trabajadores. Santiago, Chile: Dirección del Trabajo.

Echeverría, M. (2013). Subcontratos. La vía chilena a la flexibilidad laboral y el nuevo sindicalismo. En J. Ossandóny E. Tironi (eds.). Adaptación. La empresa chilena después de Friedman (pp. 249-268) Santiago, Chile: Universidad Diego Portales.

Garretón, M. (2012). Neoliberalismo Corregido y Progresismo Limitado: Los Gobiernos de la Concertación en Chile, 1990 - 2010. Santiago, Chile: ARCIS - CLACSO - PROPAL.

Godoy, L., Stecher, A., Toro, J. P. y Díaz, X. (2014). Sentidos del trabajo, identidades y vínculo social. Una mirada al trabajo en el Chile actual desde el género, la generación y el estatus ocupacional de los trabajadores. En A. Stechery L. Godoy (eds.). Transformaciones del trabajo, subjetividad e identidades. Lecturas psicosociales desde Chile y América Latina. (posición 5020-6004) Santiago, Chile: RiL.

Harvey, D. (1992). Los límites del capitalismo y la teoría marxista. Ciudad de México, México: Fondo de Cultura Económica.

Iranzo C. y Richter, J. (2012). Las implicaciones de la subcontratación laboral. En J.C. Celis (coord.). La subcontratación laboral en América Latina: miradas multidimensionales (pp. 41-68) Medellín, Colombia: CLACSO. Recuperado de http://www.izt.uam.mx/sotraem/NovedadesEditoriales/Subcontratacion.pdf 
Johnson, J.V. y Hall E.M. (1995).Class, work and health. En B. Amick, S. Levine, A.R. Tarlovy D. Chapman Walsh (coord.). Society and Health. (pp. 247-271). New York, USA: Oxford University Press.

Kalleberg, A. (2012). Globalización y trabajo precario: Desafíos para la sociedad y la sociología. En A. Cárdenas, F. Link y J. Stillerman (Eds.) ¿Qué significa el trabajo hoy? Cambios y continuidades en una sociedad global (pp. 41-53). Santiago, Chile: Catalonia.

Karasek, R.A. (1979). Job demands, job decision latitude and mental strain: Implications for job redesign. AdmSci Quart, 24, 285-308. doi: 10.2307/2392498

Kristensen, T.S., Hannerz, H., Høgh, A. y Borg, V. (2005).TheCopenhagenPsychosocialQuestionnaire-a tool for assessment and improvement of the psychosocial work environment. Scand J Work Environ Health, 31(6): 438-49. doi:10.5271/sjweh.948

Lay, S. L., Trebilcock, M. P., Olivares, A. y Durán, G. (2014). El subcontrato: impacto en la formación de identidad social basada en el trabajo. Introducción. En $8^{\circ}$ Congreso de Sociología La Serena 2014 y Encuentro PreALAS 2015.Recuperado de http://congresosociologia.servicioit.cl/archivos/gt25/GT25SuiLayBarrigaMariaTrebilcockGac-AbelMatiasOlivaresRoca.pdf

Leiva, S. (2009). La subcontratación en la minería en Chile: elementos teóricos para el análisis. Polis, 8(24), 111-131.

Mayring, P. (2000). QualitativeContentAnalysis. Forum: Qualitative Social Research, 1(2), art. 20.Recuperado de http://nbn-resolving.de/urn:nbn:de:0114-fqs0002204

Moncada S., Llorens C., Navarro A. y Kristensen T.S. (2005). ISTAS21: Versión en lengua castellana del cuestionario psicosocial de Copenhague (COPSOQ). ArchPrev Riesgos Labor, 8, 18-29.

Moncada S., Llorens C., Navarro A. yKristensen T.S. (2002). Método ISTAS21 (CoPsoQ). Manual para la evaluación de riesgos psicosociales en el trabajo. Navarra, España: Paralelo Edición. Recuperado de http:// www.istas.net/web/abreenlace.asp?idenlace=1435

Neffa, J. (2012). La subcontratación, tercerización y precarización del trabajo y el empleo: una visión regulacionista desde la economía del trabajo y el empleo. En J. C. Celis(coord.). La subcontratación laboral en América Latina: miradas multidimensionales. (pp. 69-99). Medellín, Colombia: CLACSO. Recuperado de http:// www.izt.uam.mx/sotraem/NovedadesEditoriales/Subcontratacion.pdf

Pérez-Franco, F. (2016). Nuevos trabajos, nuevos riesgos. Chile y los factores de riesgo psicosocial laboral. RevChil Salud Pública, 20(1), 36-44.

Sennett, R. (2000). La corrosión del carácter. Las consecuencias personales del trabajo en el nuevo capitalismo. Barcelona, España: Anagrama.

Siegrist, J. (1996). Adverse health effects of high effort-low reward conditions. J Occup Health Psychol, 1, 27-41. doi:10.1037/1076-8998.

Sisto, V. (2013). Entre la privatización y la reconstrucción de lo público en Chile: Movimientos estudiantiles y el debate acerca del devenir de la universidad. HorizontesSociológicos, 1(1), 57-71.

Slaughter, S. y Leslie, L. (1999).Academic Capitalism: Politics, Policies, and the Entrepreneurial University. Baltimore, USA: Johns Hopkins University Press.

Soto, A., Espinoza, G. y Gómez, J. (2008). Aspectos subjetivos vinculados a la flexibilidad laboral. En A. Soto (ed.). Flexibilidad laboral y subjetividades. Hacia una comprensión psicosocial del empleo contemporáneo (pp. 11-37) Santiago, Chile: LOM Ediciones. 
Superintendencia de Seguridad Social. (s. f.). ISTAS SUSESO 21. Chile.Recuperado de http://www.suseso.cl/sel/ 604/w3-article-40851.html

Waissbluth, M. e Inostroza, J. (2007). Globalización y reforma del Estado en Chile. Iberoamericana. Nordic Journal of Latinoamerican and Caribbean Studies.XXXVII(1), 285-310. doi: 10.16993/ibero.205 